\title{
Innovative Design of Modern Mortise and Tenon Structure under the Concept of Green Reduction
}

\author{
Wei Wu, Jian'gang Zhu, ${ }^{*}$ Wei Xu, Fei Han, Xinghuan Wu, and Xu Wang \\ In the furniture industry, some traditional Chinese mortise and tenon joints \\ are not suitable for the current requirements for carbon reduction and \\ environmental protection of furniture products. This article aims to explore \\ new ideas and new methods of modern mortise and tenon structure design. \\ The reduction principle in the green design concept is introduced for the \\ furniture modern mortise and tenon structure design. Based on modern \\ furniture, a systematic analysis of the modern mortise and tenon structure \\ design is carried out. Additionally, this review discusses the method of \\ applying the reduction principle in modern tenon and tenon structure \\ design in the context of green design. The development status and trend \\ of modern mortise and tenon structure design is summarized and an \\ innovative design practice of modern mortise and tenon structure is carried \\ out. The combination of green design and furniture design has important \\ practical significance in a modern context.
}

Keywords: Reduce; Mortise-and-tenon joint; Innovative design

Contact information: College of Furnishings and Industrial Design, Nanjing Forestry University, Nanjing 210037, China; *Corresponding author: austin_zhu@njfu.com.cn

\section{INTRODUCTION}

While creating a modern lifestyle and living environment for mankind, industrial society is accelerating the consumption of resources and energy, causing great damage to the environment. In recent years, as countries around the world continue to spread knowledge about green, environmental protection and ecology to people, human concepts of ecological civilization have begun to change. Many people have gradually realized that there are serious consequences of the unrestrained use of natural resources and the unrestricted pursuit of material enjoyment. The idea of burning forests and fields is out of fashion. If this goes on, humans will eventually suffer from it and fall into a serious ecological crisis and environmental crisis (Huang 2011), which not only endangers the survival of animals and plants but can also be regarded as a crisis of human existence.

In the era of underdeveloped industry, the traditional Chinese mortise and tenon structure has been developed for thousands of years, and it can be said to be quite mature, especially in furniture. However, in the current era of industrialization, automation, and information technology, the modern application of the traditional mortise and tenon structure is not optimistic. Breaking through this rigid state is an urgent problem (Yu and Lyu 2016). One of the methods is to reduce the design of solid wood furniture structure, and it can alleviate the imbalance between supply and demand of China's timber resource shortage. On the other hand, Chinese traditional wood structure construction techniques comprise a world-class intangible cultural heritage. Chinese domestic craftsmen and enterprises just shout protection slogans, but the actual protection and publicity of it is not ideal. For Chinese designers, the most important and most difficult thing is to integrate 
traditional classical techniques into modern life (Wang 2018). Accordingly, there is a need for design of mortise and tenon structures that are more in line with modern requirements.

\section{CHALLENGES OF TRADITIONAL MORTISE AND TENON STRUCTURE}

\section{Complex Structure}

Although the development of the mortise and tenon structure is very mature, after experiencing the era of luxury during the Qing Dynasty, some mortise and tenon structures with complex structures and extremely graceful and luxurious decorations have appeared. The mortise and tenon structures that can be produced in batches by machinery are mostly straight tenons and round tenons. However, it is still difficult to achieve mechanized mass production for complex structures such as clip tenons and dumpling corner tenons. Although $\mathrm{CNC}$ lathes are powerful and can realize the processing of complex and specialshaped parts, the cost also increases. As shown in Fig. 1, the embracing-shoulder tenon includes waistbands and tooth bars. The five components of the joint need to be interspersed with each other, and the seven mortise holes with corresponding tenon tongues have a different size, depth, and shape (Xu et al. 2018). The structure is complex, and the manufacturing process is complicated.

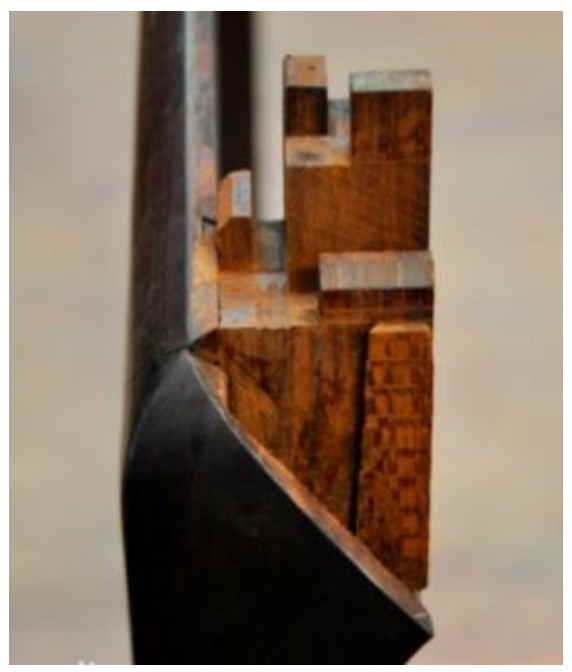

Fig. 1. Embracing-shoulder tenon

\section{Unreasonable in Design}

Even with the affordable luxury style and new Chinese style that have prevailed in recent years, there is still a phenomenon that the appearance and decoration of the structure is not incorporated, however, the internal connection structure continues to use the traditional mortise and tenon structure. This phenomenon has been used as a gimmick by the enterprise (Li et al. 2018). This makes the modern application of the traditional mortise and tenon structure rigid. The design is generally not very complicated and lacks scientific grounding, which leads to the simplification of the mortise-and-tenon structure so that it cannot achieve good bonding strength. As a consequence, glue, nails and some connectors are needed to supplement the joint strength. This increases the complexity of the overall structure and increases the number of parts. 


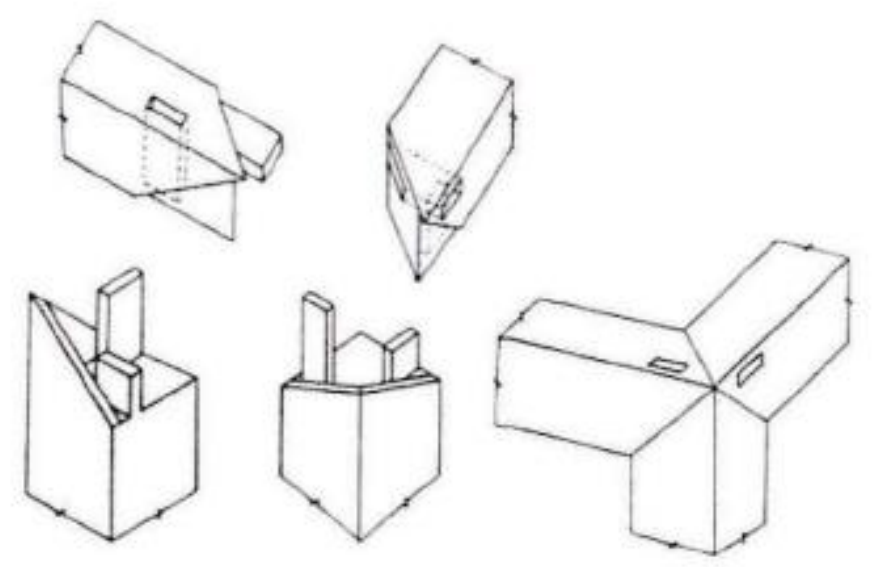

Fig. 2. Mortise-and-tenon joint at which three square members meet at one corner

\section{High Processing Cost}

Traditional mortise and tenon components are made by hand. Certain complicated mortise and tenon structure can only be made by hand. To improve the work efficiency of mortise-and-tenon joints, the production process must meet the requirements of large-scale mechanized production. However, under the modern production technology, there are many mortise-and-tenon structures that are difficult to achieve by mechanized molding. Figure 2 shows the shape of the mortise-and-tenon joint at which three square members meet at one corner, the joint surface of the tenon is $45^{\circ}$ inclination, and the internal details are complicated and cumbersome. Such tenon joints are usually completed by experienced woodworkers. Modern machinery is difficult to complete within 1 to 2 processing procedures (Liu 2015), so the processing cycle is long, which will inevitably lead to a substantial increase in costs. The complex mortise and tenon structure requires a CNC machine tool or a skilled woodworker to make it semi-manually. The former equipment is expensive, and many domestic furniture manufacturers cannot afford it. The latter has high labor costs, and manufacturers often use it as a sales gimmick to raise prices.

\section{High Transportation Cost}

As an inseparable part of modern furniture production, packaging plays an important role in ensuring the storage, transportation, and sales of goods at all stages. The transportation and packaging of furniture mainly include furniture outer packaging containers, furniture packaging protective materials, and auxiliary packaging materials. Although most of the tenon and tenon joints are removable, there is no uniform, reasonable, and scientific method for placing the components in the packaging container. Instead, the workers divide them according to the actual size and material of the furniture components to form one or several packaging boxes. The set is transported and finally assembled into a whole in the hands of the user. For furniture with mortise and tenon structure or heterogeneous parts that are difficult to disassemble and assemble and have large parts, more integrated transportation is used, and flat transportation is used less. There are problems in the space occupied by transportation and placement, and the transportation cost is high. The current situation of furniture packaging recycling is not ideal; it cannot be used twice, and it is easy to cause environmental pollution (Gao et al. 2015). 


\section{GREEN DESIGN AND REDUCTION PRINCIPLE}

\section{Green Design}

Outside of China, people have realized the importance of green for a long time. In 1917, David McTaggart established the international "Greenpeace Organization". The first Human Environment Conference in June 1972 officially kicked off the prelude to the protection of the environment by mankind and issued the famous "Declaration of the Human Environment." As part of this declaration, June $5^{\text {th }}$ of each year was established as World Environment Day (Yan 2016). In the 1960s, the American design theorist Victor Papanek's monograph "Design for the Real World" (Papanek 2012) emphasized that design should be linked to ecological protection.

In the early 1980s, China also began to carry out green transformation of traditional industries. Although there are few systematic monographs on theory, there are as many as 15,000 papers on green design and green furniture design. For example, in the article "Current Situation and Problems of my country's Furniture Industry FSC Chain of Custody Certification," Wang Jing tried to regulate the market by building an authoritative green certification system, thereby promoting the upgrading of industrial structure and sustainable development (Wang and $\mathrm{Wu} 2013$ ). People in the $21^{\text {st }}$ century desire green furniture products that are healthy and safe, environmentally friendly, comfortable, safe, and efficient.

Green design is also called ecological design, design for environment, and environment conscious design (Liu 2020). These designations can be simplified to the "4R principle," that is, reduce, reuse, recycle, and regenerate. During the entire life cycle of the product "from cradle to regeneration", the focus is on environmental attributes such as product disassembly, recyclability, maintainability, reusability, etc. (Wang et al. 2019), to minimize material and energy consumption, and reduce hazardous material emissions, while ensuring the product's due performance, life, quality, and other requirements.

There are seven requirements for green design: 1) Use natural materials; 2) Concise style; 3) Practical and energy-saving; 4) Emphasize the economical use of materials; 5) Refusal of product abolition; 6) Dematerialization of products and services; and 7) Combination design and cycle design.

\section{Reduction Principle}

Overview

Among the "4R Principles", the reduction principle is ranked first among the principles, and it is the core of green design in the whole life cycle; the purpose of the reduction principle is to try to reduce the amount of input into the production and consumption links from the source. Material flow and energy flow are also integral to the principle of circular economy. The principle of reduction is to use less raw materials and energy inputs to achieve established production goals or consumption goals, thereby saving resources and reducing pollution. For example, in the production process, by reducing the weight, area, and quantity of materials, the process will generate savings in production, circulation, consumption, and energy usage. The guiding ideology of reduction design is to protect the environment and achieve sustainable development. Making the best use of the material is the core idea. It is not to reduce the production goals, tasks, product structure, and materials of the enterprise, but to make the products more reasonable, the model structure simpler, the furniture product functions more reasonable, the structure stronger, and the service life longer (Dong 2013). 


\section{The embodiment of the principle of reduction}

The principle of reduction is embodied in four aspects:

(1) Remove the decoration of the product: abandon extravagant and useless decorations and simplify the design to shorten the design cycle and simplify the process. The style is fresh and elegant, rejecting the grace and luxury of classicism. Simplify the post-processing, packaging, and transportation of products to achieve energy saving (Wang 2013).

(2) Reduce parts: while ensuring form and function, in terms of structure, reduce the size of parts that are not load-bearing or have a small effect. Optimize the number and dimensions of components and reduce material consumption.

(3) Shorten processing time: shorten the raw material preparation process, shorten the product processing process, shorten the life cycle of transportation and sales links, etc., to reduce the energy consumption of furniture products in the whole life cycle.

(4) Reduce packaging volume: reduce packaging volume, save labor consumption during processing, improve production efficiency, reduce logistics costs, save storage space for furniture products, and facilitate transportation and storage. Flat packaging is common.

\section{MODERN MORTISE AND TENON STRUCTURE}

\section{The Difference between Modern and Traditional Mortise and Tenon Structure}

The so-called modern mortise and tenon structure does not completely deviate from the traditional mortise and tenon structure. Rather, it refers to a type of mortise-and-tenon structure that is convenient for mechanized and automated production, handling, assembly, and storage. The development of modern mortise and tenon structure is affected by the current situation of the shortage of wood resources, the industrialized production environment, the development and design direction of mechanical equipment, cutter heads, and auxiliary materials. Lyu (2018) classified the traditional mortise and tenon joint structure into 41 types according to the different types of joints, and the modern mortise and tenon joint structure was divided into 3 categories and 33 types:

(1) Keep the traditional categories: rectangular mortise and tenon joint, unhidden tenon, straight shoulder joint, mortise-and-tenon joint at which three square members meet at one corner, mitred tenon, peg tenon joint used on curved members, dovetail tenon, cross tenon, planted tenon, wedged tenon, etc.

(2) Traditional improvements: penetrating transverse brace tenon, double-mitred tenon, embracing-shoulder tenon, etc.

(3) New categories: finger joint, round mortise and tenon joints, component tenon, wooden dowel, sheet tenon, U-shape tenon, inserted tenon, etc.

\section{The Principle of Reduction in Modern Mortise and Tenon Structure}

The reduction design of the mortise and tenon structure refers to the reduction and optimization design from the material, shape, and size of the structure under the conditions of meeting the basic functions of the furniture product, the safety and stability of the structure, and the aesthetics of the public. This is done in order to achieve the purpose of saving wood, reducing costs and reducing pollution (Liu et al. 2015). Specifically, it can be divided into the following four types. 


\section{Simplified decoration}

For classical furniture, Ming-style furniture is full of the scent of literati; it has simple lines, beautiful and tall shapes; it is well-proportioned and coordinated, and it hides the "internal beauty" and "cultivation" of Chinese culture. Compared with Qing-style furniture, this simple style of Ming-style furniture is more suitable for the needs of current users and enterprises. Too much decoration is more likely to cause visual fatigue. Modern furniture should not only be moderately restrained on decoration as a whole but also on the decoration of parts and components. The area of decoration such as carvings, inlays, and moldings should be as small as possible (Zhan et al. 2021).

\section{Simplified structure}

By simplifying the structure of the tenon joint, the following reductions can be achieved.

1. Reduce production time: The production assistance time has the greatest impact on production efficiency. Under normal circumstances, production assistance time accounts for about $70 \%$ of the total processing time, machining time only accounts for about $30 \%$, and the actual wood cutting time is about $5 \%$. The auxiliary production time is composed of the time of tool adjustment and machine adjustment, production end time, first confirmation time, and cleaning time (Wei and Li 2018). The most important thing is to reduce the time of tool adjustment and machine adjustment. The methods are divided into three methods, as shown in Table 1.

2. Reduce the size of parts: most of the furniture using the mortise and tenon structure is solid wood furniture. At the same time, it is affected by the heavy style of classical furniture. Compared with panel furniture, solid wood furniture has larger parts and excessive materials. The rated load often exceeds the bearing load (static load and dynamic load) of the national standard design furniture. Through finite element analysis, under the premise of ensuring the functional integrity and safety of furniture, the scale of parts can be reduced scientifically, and some structures can even be eliminated to reduce material consumption ( $\mathrm{Hu} 2020)$.

3. Standardization and modularization: Under the guidance of science, designers actually have less space to play. The simplified mortise and tenon structure makes it easier to achieve standardization. Of course, standardization comes with a lack of innovation and special sense of different furniture. But designers from group technology, interchange design, digital and modular four directions to start, by adding furniture fun, lower prices of furniture, replacement parts extend the life of furniture, etc., to improve the competitiveness of furniture products (Wang and Zhong 2020).

\section{Simplified disassembly}

The purpose of this type of tenon and tenon structure is to optimize the assembly process of furniture products, reduce the professional difficulty of the disassembly and assembly process, and enable users to disassemble and assemble themselves without onsite service, thereby reducing the carbon footprint of the product and making the product more interesting. This kind of furniture products basically do not need sizing, thereby reducing the use of harmful substances and formaldehyde emissions. IKEA has been committed to this aspect of research for a long time. 
Table 1. Classification of Ways to Reduce Tool Adjustment Time

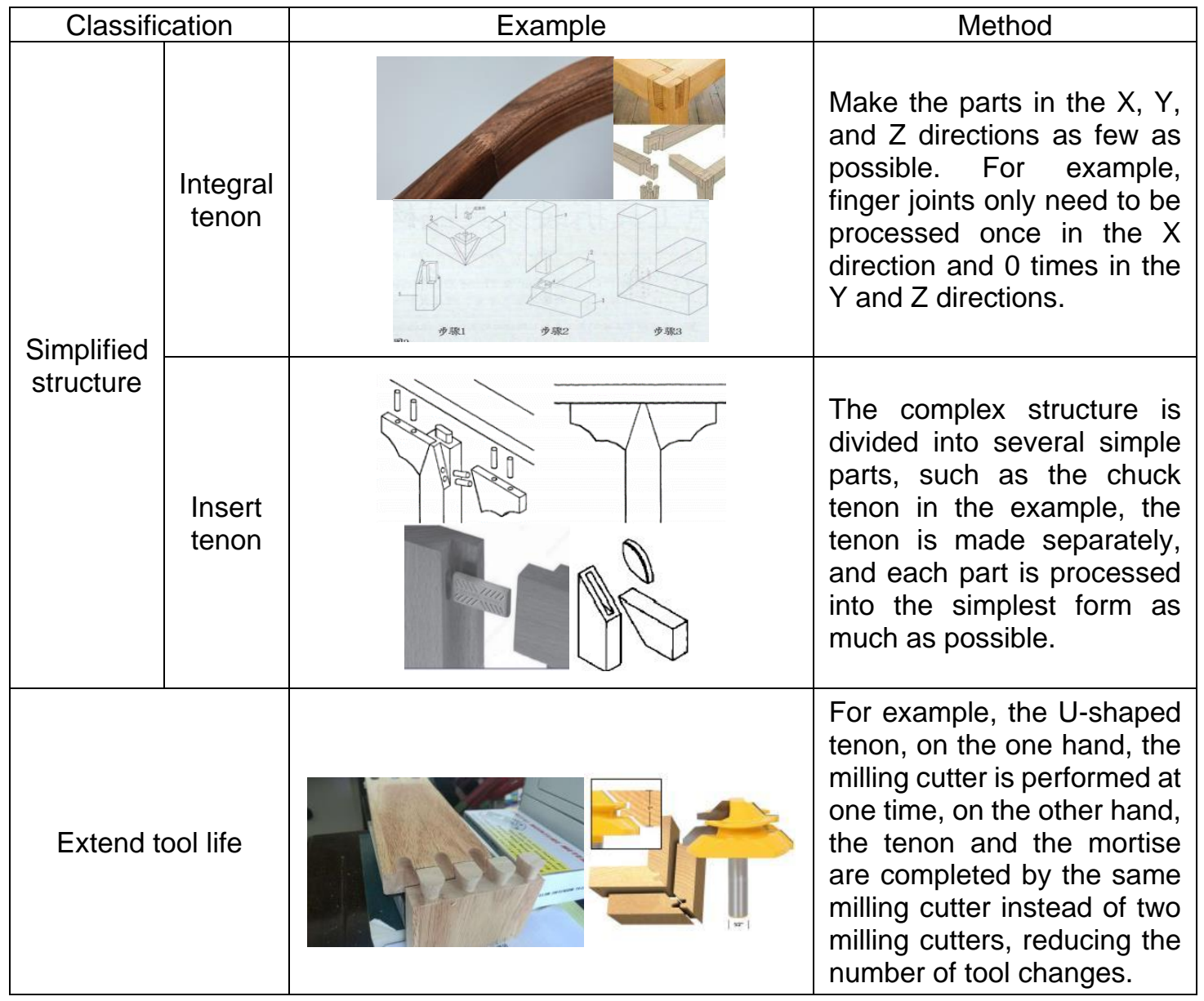

As shown in Fig. 3, IKEA's wedge-shaped wooden dowels use the principle of tenon and screw in combination. In fact, they are more like the improvement of wedged tenon, with a wave-shaped tooth pattern. This structure can save resources and consume less wood material, which can prolong the service life of furniture. As shown in Fig. 4, IKEA's LISABO series uses dovetail dowels, which can increase assembly speed by $80 \%$ and shorten assembly time ( $\mathrm{Li} 2020)$. The product itself does not require nails or glue, and it can be installed manually and without tools. Its dismountable feature is not only convenient for transportation, but also it can increase the fun of assembly for users, which is the embodiment of the convenience of disassembly and assembly of the mortise-andtenon structure.

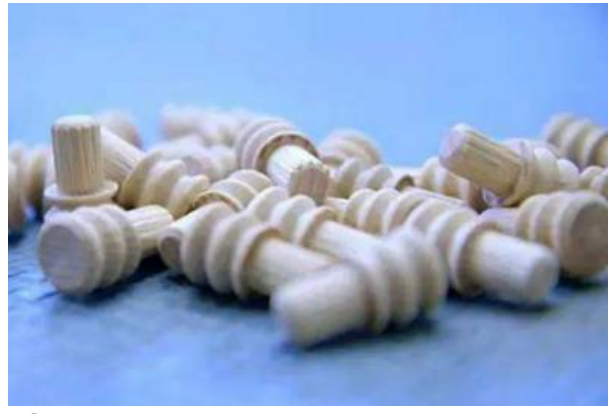

Fig. 3. Wedge dowel

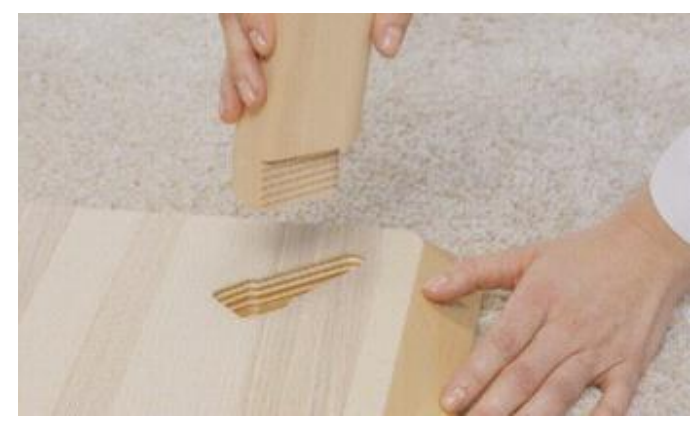

Fig. 4. LISABO series 


\section{Simplified packaging}

To design flat furniture, the standardization, versatility, and serialization of parts must be realized first, so that the specifications and quantities of product parts can be simplified. The design work is simplified accordingly. The specifications of parts are simplified, and the quality control is facilitated during production. Improving the processing accuracy and productivity prolongs the service life of the equipment and reduces product costs. Standard specifications of packaging are easy to stack, which effectively uses space, reduces the trouble of handling, and reduces product damage. The product manual allows consumers to participate in the design and realize the peopleoriented design concept. Plain furniture has many advantages in design, production, storage, transportation, sales, and installation. It can adapt to modern large-scale industrial production, but also has important significance for environmental protection, which is unmatched by traditional frame furniture (Xu 2015). Common practices are shown in Table 2 .

Table 2. Flat Packaging Structure

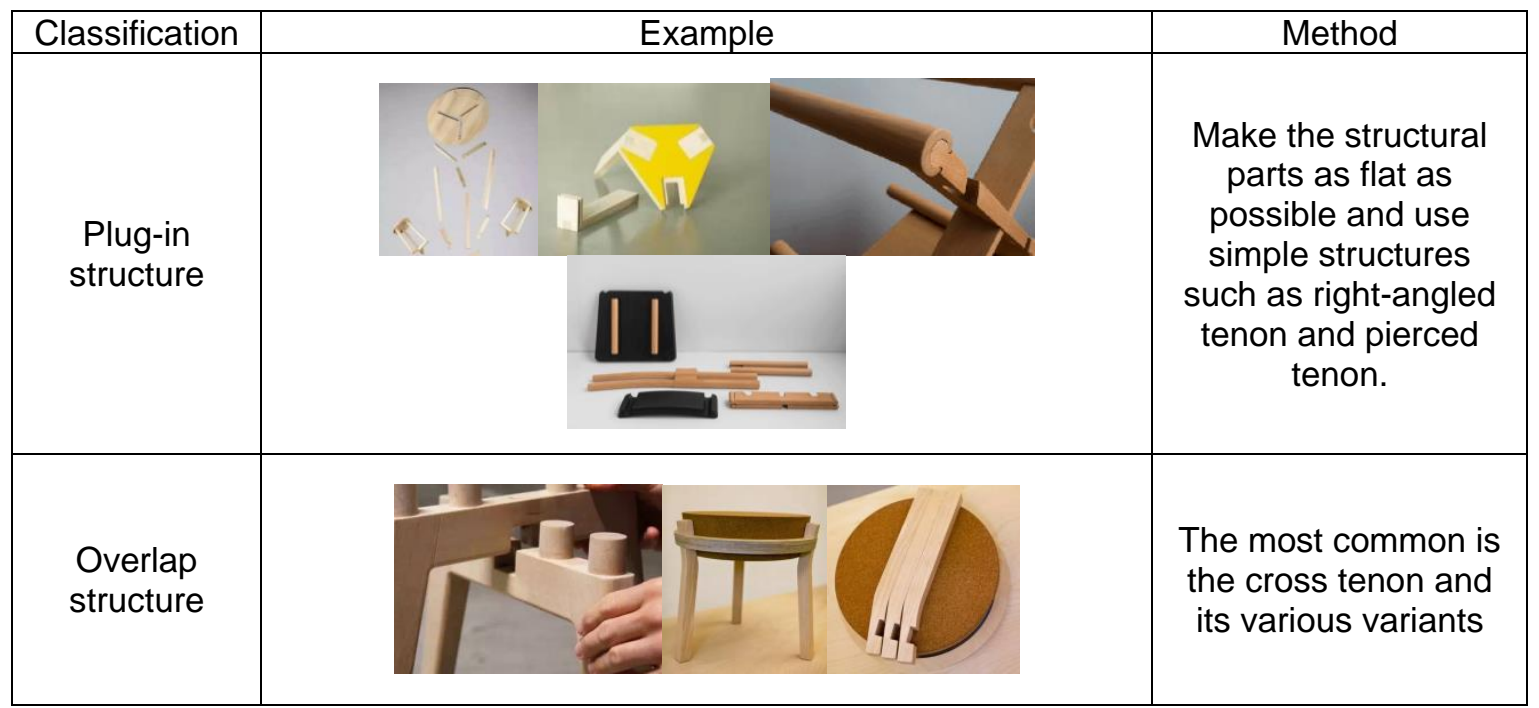

\section{DESIGN CONSIDERATIONS}

Under the requirements of the reduction principle of green design, a mortise-andtenon structure for connecting the chair legs, the cross brace and the seat surface is designed to realize the assembly line processing of the parts. By optimizing the mortise-and-tenon structure, it saves materials and improves industrial production efficiency. At the same time, the self-locking feature of the mortise-and-tenon is used to ensure that the new mortise and tenon joints have sufficient bonding strength and structural stability in all directions. A self-locking modern press tenon is a redesigned structure. (This design has applied for a Chinese utility model patent.)

\section{Size Description}

As shown in Fig. 5, the chair design includes chair legs A, crossbar 1B, crossbar $2 \mathrm{C}$, and seat surface $\mathrm{D}$. The cross section of the chair leg $\mathrm{A}$, the longitudinal section of the crossbar $1 \mathrm{~B}$ and the longitudinal section of the crossbar $2 \mathrm{C}$ are all $40 \mathrm{~mm} \times 40 \mathrm{~mm}$ square. 
The top of the chair leg A is provided with a square cross-section tenon one A-1 and tenon two A-2. The two tenons are located at two diagonal positions on the top of the chair leg A. The two tenons are the same in size, with a size of $12 \mathrm{~mm}(\mathrm{~L}) \times 12 \mathrm{~mm}(\mathrm{~W}) \times 60 \mathrm{~mm}(\mathrm{H})$.

One end of the crossbar $1 \mathrm{~B}$ is provided with a tongue groove $1 \mathrm{~B}-1$ for matching with a tenon head A-1 and a groove $2 \mathrm{~B}-2$ with a trapezoidal cross section. The depth of the two tongue groove B-2 is $40 \mathrm{~mm}$, and the cross section is trapezoidal. The upper base side length $\mathrm{I}$ is $12 \mathrm{~mm}$, and the included angle between one of the waist and the lower base is $70^{\circ}$, which is the same shape and size as the tenon $3 \mathrm{C}-1$ on the crossroad $2 \mathrm{C}$.

One end of the crossbar $2 \mathrm{C}$ is provided with a tenon $3 \mathrm{C}-1$ for matching with the tenon groove $2 \mathrm{~B}-2$, and the tenon $3 \mathrm{C}-1$ is provided with a tenon groove $3 \mathrm{C}-2$ for matching with the tenon $2 \mathrm{~A}-2$, as shown in Fig. $4 \mathrm{~b}$. The seat surface $\mathrm{D}$ is provided with a tongue groove $4 \mathrm{D}-1$ and a tongue groove 5D-2 for matching with the tenon $1 \mathrm{~A}-1$ and the tenon $2 \mathrm{~A}-2$ respectively. The two tenons have the same size, and the size is $12 \mathrm{~mm}(\mathrm{~L}) \times 12 \mathrm{~mm}$ $(\mathrm{W}) \times 20 \mathrm{~mm}(\mathrm{H})$. The dimensions of the groove $1 \mathrm{~B}-1$ on the crossbar $1 \mathrm{~B}$ and the groove $3 \mathrm{C}-2$ on the crossbar $2 \mathrm{C}$ are the same; the size is $12 \mathrm{~mm}(\mathrm{~L}) \times 12 \mathrm{~mm}(\mathrm{~W}) \times 40 \mathrm{~mm}(\mathrm{H})$.

\section{Assembly Method}

The tongue and groove $1 \mathrm{~B}-1$ of the crossbar $1 \mathrm{~B}$ is inserted with the tenon $1 \mathrm{~A}-1$ of the leg $\mathrm{A}$, the tongue and groove $2 \mathrm{~B}-2$ of the crossbar $1 \mathrm{~B}$ is inserted with the tenon $3 \mathrm{C}-1$ of the crossbar $2 \mathrm{C}$, and the tongue and groove $3 \mathrm{C}-2$ of the crossbar $2 \mathrm{C}$ is inserted into the tenon 2A-2 of the chair leg A, and the crossbar 1 and the crossbar 2 form a self-locking fit and squeeze tightly. The tongue and groove $4 \mathrm{D}-1$ of the seat $\mathrm{D}$ is inserted into the tenon $1 \mathrm{~A}-1$ of the leg $\mathrm{A}$, the tongue and groove $5 \mathrm{D}-2$ of the seat $\mathrm{D}$ is inserted into the tenon $2 \mathrm{~A}-$ 2 of the leg $\mathrm{A}$, the crossbar $1 \mathrm{~B}$, the crossbar $2 \mathrm{C}$ and the legs $\mathrm{A}$ are located below the seat D.

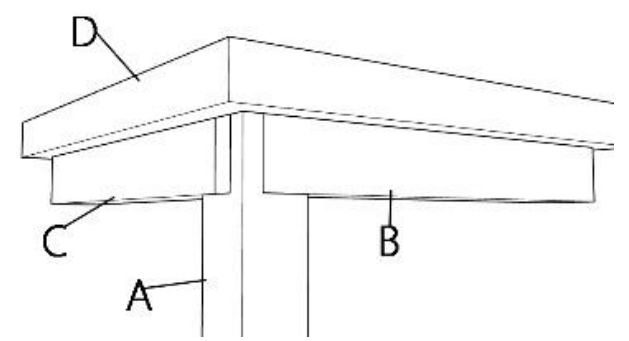

a) Front view

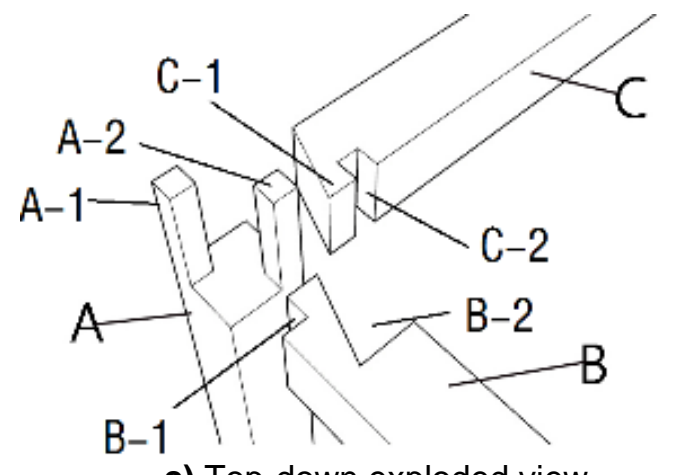

c) Top-down exploded view

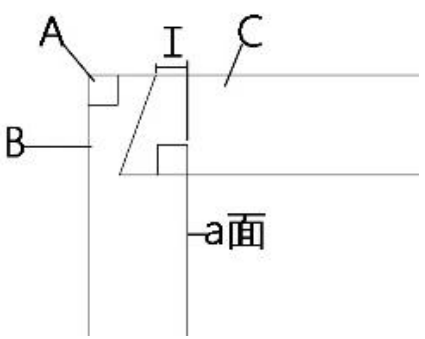

b) Top view

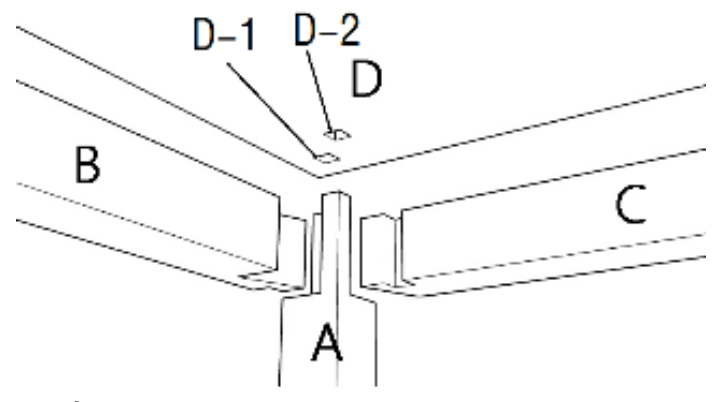

d) Looking up at the exploded view

Fig. 5. The mortise-and-tenon joint designed by the authors 


\section{CONCLUSIONS}

1. The improved mortise and tenon structure has achieved extreme restraint in decoration, and the connecting parts of parts $\mathrm{A}, \mathrm{B}$, and $\mathrm{C}$ are all composed of straight lines, in which the cutting tools of parts $\mathrm{B}$ and $\mathrm{C}$ can be fixed during machining. This approach saves time of the production assistant, as a result of adjusting the knife. Parts A, B, and $\mathrm{C}$ are designed through modularization and standardization, making themselves not only the smallest parts, but also the parts that make up the furniture, which is more suitable for assembly line production. Parts A, B, and C can obtain good stability through self-locking, and each part does not need glue or dowels, rendering the completed chair easy to disassemble and assemble again.

2. Achieving simplification, light weight, small size, and simplicity of furniture is the goal of reduced-quantity design, but the ultimate target of green design is people. Therefore, "people-oriented" humanized design is equally important, which extends to society and the environment. In the design process, one must pay attention to the entire society and the natural environment, with the lowest possible consumption of raw materials and energy, to meet the requirements of product functionality, safety, comfort, economy and aesthetics, and abandon the flashy appearance. The goal is to attract customers through product performance, price, and quality.

3. Mortise and tenon structure are the inheritance of Chinese wooden structure, which embodies rich and profound design ideas, and its harmonious design ideas make modern products more cultural. As the public pays more attention to the concept of green design, the use of wood structures has become more and more widespread, and the carrying capacity of modern tenon and tenon structures has been improved. Compared with traditional tenon and tenon structures, it has also developed and innovated in shape, such that it can be better integrated into modern furniture design. However, while the modern mortise and tenon structure makes rational use of green design, saves resources, and improves product market competitiveness, there are still many areas for improvement and innovation. At the same time, after investigation, it is found that countries in the world, especially Japan, are committed to the research of new green mortise and tenon structure, so it is necessary to increase the research on green mortise and tenon structure, which is also to protect our own cultural heritage.

\section{ACKNOWLEDGMENTS}

The authors are grateful the support of the Joint Research program of Sino-foreign Cooperation in Running Schools of Jiangsu Province, China.

\section{REFERENCES CITED}

Dong, Z. (2013). On the Design of Plain Furniture Based on the Principle of Reduction, Master's Thesis, Nanjing University of the Arts, Nanjing, China.

Gao, X. Y., Liu, J. Y., and Cai, J. R. (2015). "Research and discussion on the design of panel furniture transport packaging," China Packaging Industry 23(20), 25-26.

DOI: $10.14047 /$ j.cnki.cpi.20151214.001

Wu et al. (2021). "Green design of mortise \& tenon," BioResources 16(4), 8445-8456. 
Huang, S. Y. (2011). A Study on the Design of New-Sino-Style Furniture Made of Recombinant Bamboo, Ph.D. Dissertation, Nanjing, China.

$\mathrm{Hu}$, Y. H. (2020). "Research on furniture design based on the concept of green design," Packaging Engineering 41(10), 345-348. DOI: 10.19554/j.cnki.10013563.2020.10.058

Li, H., and Dong, H. J. (2018). "Problems and enlightenment in the inheritance of mortise and tenon structure of Chinese traditional furniture," Industrial Design 13(4), 33-34.

Li, W. L. (2020). "Application of mortise and tenon structure in modern furniture design," Design 33(8), 102-104.

Liu, Q. Y. (2015). "Analyze the inheritance and innovation of mortise and tenon structure in modern furniture design," Beauty \& Times 1(8), 63-64.

Liu, Y. (2020). "Innovative applications of green design-based manufacturing products," China Metal forming Equipment \& Manufacturing Technology 55(4), 129-131. DOI: 10.16316/j.issn.1672-0121.2020.04.032

Liu, D. Y., Li, K. Z., Peng, Y., and Peng, Z. Y. (2015). "Reduction design of solid wood furniture," Furniture \& Interior Design 22(6), 26-27. DOI: 10.16771/j.cnki.cn43$1247 /$ ts.2015.06.006

Lyu, J. F. (2018). Mortise and Tenon Joint of Chinese Traditional Furniture, Shanghai Science and Technology Press, Shanghai.

Papanek, V. (2012). Design for the Real World, CITIC Publishing House, Beijing. Wang, T. T. (2018). Connotation and Appearance_-Research on the Application of Innovative Tenon and Tenon Structure in Modern Furniture Design, Master's Thesis, Nanjing University of the Arts, Nanjing, China.

Wang, J., and Wu, Z. H. (2013). "Current status and problems of FSC production and marketing chain of custody certification in the furniture industry in my country," Journal of Forestry Engineering 27(1), 5-9.

Wang, S., Chen, L., and Wu, Z. H. (2019). "Application of green design concept in furniture structure design," Industrial Design 14(11), 101-102.

Wang, X. Y. (2013). The Green Design of Research Based on the Whole Life Cycle of Furniture, Master's Thesis, Dalian University of Technology, Dalian, China.

Wang, L. Y., and Zhong, S. L. (2020). "Exploration on disassembly property of sofa frame structure," Furniture \& Interior Design 27(3), 68-69. DOI: 10.16771/j.cn43$1247 /$ ts.2020.03.020

Wei, D. M., and Li, J. (2018). "Analysis of different batches of solid wood lines on labor costs," Furniture \& Interior Design 25(1), 116-117. DOI: 10.16771/j.cn43$1247 /$ ts.2018.01.026

$\mathrm{Xu}, \mathrm{J}$. (2015). "Research on standardization of assembly and disassembly on RTA furniture," Standard Science 22(8), 35-38, 50.

$\mathrm{Xu}$, Y. M., Dong, H. J., and Wang, B. C. (2018). "Study on problems in the development of the traditional mortise and tenon structure," Furniture \& Interior Design 25(7), 60-61. DOI: 10.16771/j.cn43-1247/ts.2018.07.006

Yan, Y. L. (2016). The Research about the Ecologicalization of China's Furniture Industry, Master's Thesis, Nanjing University of the Arts, Nanjing, China.

Yu, M. N., and Lyu, J. F. (2016). "The inspiration of green design connect to the He modernization of mortise-tenon structure," Furniture 37(4), 66-69. DOI: 10.16610/j.cnki.jiaju.2016.04.014 
Zhan, X. L., Dai, X. D., Hu, Y. J., and Li, M. X. (2021). “The inspiration of green design connect to the He modernization of mortise-tenon structure," Furniture \& Interior Design 28(5), 5-9. DOI: 10.16771/j.cn43-1247/ts.2021.05.002

Article submitted: June 23, 2021; Peer review completed: August 2, 2021; Revised version received and accepted: August 21, 2021; Published: August 26, 2021.

DOI: $10.15376 /$ biores.16.4.Wu 